\title{
Retropubic, Laparoscopic, and Robot-Assisted Radical Prostatectomy: Surgical, Oncological, and Functional Outcomes: A Systematic Review
}

\author{
Francesco De Carlo $^{a}$ Francesco Celestino $^{b}$ Cristian Verri ${ }^{a}$ Francesco Masedu $^{c}$ \\ Emanuele Liberati ${ }^{b}$ Savino Mauro Di Stasi ${ }^{a}$ \\ ${ }^{a}$ Department of Experimental Medicine and Surgery, Tor Vergata University, and ${ }^{b}$ Operative Unit of Urologic \\ Oncology, Policlinico Casilino, Rome, and 'Department of Medicine and Public Health, University of L'Aquila, \\ L'Aquila, Italy
}

\section{Key Words}

Laparoscopy · Prostate cancer - Prostatic adenocarcinoma . Radical prostatectomy - Radical retropubic prostatectomy . Sexual function · Surgery · Urinary incontinence

\begin{abstract}
Objectives: Despite the wide diffusion of minimally invasive approaches, such as laparoscopic (LRP) and robotassisted radical prostatectomy (RALP), few studies compare the results of these techniques with the retropubic radical prostatectomy (RRP) approach. The aim of this study is to compare the surgical, functional, and oncological outcomes and cost-effectiveness of RRP, LRP, and RALP. Methods: A systematic review of the literature was performed in the PubMed and Embase databases in December 2013. A 'freetext' protocol using the term 'radical prostatectomy' was applied. A total of 16,085 records were found. The authors reviewed the records to identify comparative studies to include in the review. Results: 44 comparative studies were identified. With regard to the perioperative outcome, LRP and RALP were more time-consuming than RRP, but blood loss, transfusion rates, catheterisation time, hospitalisation duration, and complication rates were the most optimal in the laparoscopic approaches. With regard to the functional and oncological results, RALP was found to have the best
\end{abstract}

outcomes. Conclusion: Our study confirmed the wellknown perioperative advantage of minimally invasive techniques; however, available data were not sufficient to prove the superiority of any surgical approach in terms of functional and oncologic outcomes. On the contrary, cost comparison clearly supports RRP.

(c) 2014 S. Karger AG, Basel

\section{Introduction}

Prostate cancer is the most common tumour in people aged over 50 years and the second leading cause of cancer death in Northern Europe and the United States. The increase in life expectancy, combined with the use of PSA as a screening method and the reduction of a threshold for prostate biopsy indication, has contributed to an increase in the diagnosis of prostate cancer [1]. Consequently, this has led to an increase in the number of patients who are candidates for radical prostatectomies. Radical prostatectomy (RP) is a common treatment for patients with clinically localised prostate cancer (cT1cT2) and a life expectancy $>10$ years. Open RP has long represented the most widely adopted treatment to eradicate prostate cancer. However, the progressive development of minimally invasive surgery and the continuous

\section{KARGER}

E-Mail karger@karger.com

www.karger.com/uin
(C) 2014 S. Karger AG, Basel

0042-1138/14/0934-0373\$39.50/0
Savino Mauro Di Stasi

Department of Experimental Medicine and Surgery

Tor Vergata University

Via Montpellier 1, IT-00133 Rome (Italy)

E-Mailsdistas@tin.it 
research into surgical techniques that can ensure better outcomes and fewer complications compared with the standard 'open' surgery have led several providers to apply laparoscopic techniques to RP.

In 1997, Schuessler et al. [2] performed the first laparoscopic RP to transfer the well-known advantages of the laparoscopic technique to the most common open surgical treatment for prostate cancer. Subsequently, in 1999, Guillonneau and Vallancien [3] improved the technique and obtained results similar to those of open surgery. Despite the demonstrated efficacy of laparoscopic surgery, the technique has never completely supplanted the 'open' approach. This is mainly due to the long learning curve resulting from the two-dimensional view of the field, the reduced 'range' of motion associated with the lack of tactile feedback, and the need to coordinate hand movements with screen vision, representing a difficult task for any surgeon, even the most experienced in 'open' surgery $[4,5]$.

The advent of robotic surgery is a further evolutionary step in the development of minimally invasive prostate surgery. The possibility of having a three-dimensional view of the surgical field, with a greater and more intuitive movement capability of the robotic arms, significantly reduces the learning curve $[6,7]$. On the other hand, these advantages are offset by the high cost of the ' $\mathrm{Da}$ Vinci ${ }^{\circledR}$ ' robot, which is available at few institutions [8]. Despite the considerable diffusion of laparoscopic and robotic surgery and the remarkable diversification of the surgical approach used to date, only a few studies have compared these innovative techniques with the classic 'open' approach.

The purpose of this study is to evaluate the peri- and postoperative results, including the oncological and functional outcomes, complications and cost comparison among the 'open', laparoscopic and robotic techniques.

\section{Methods}

A literature search was performed in December 2013 using the PubMed and Embase databases. The PubMed and Embase search included only a 'free-text' protocol using the term 'radical prostatectomy' across the 'Title' and 'Abstract' fields of the records. Subsequently, the only language limit used was the selection of English as the default. With these parameters, we found 12,877 records on the PubMed database; 3,208 records were retrieved from the Embase database. Two authors separately reviewed the records to select the studies comparing retropubic radical prostatectomy (RRP) to laparoscopic radical prostatectomy (LRP), RRP to robot-assisted radical prostatectomy (RALP), or LRP to RALP.
We analysed all of the papers published since 1999 to date (1999-2013), only considering the comparative articles. Studies published only as abstracts and reports from meetings were not included in this review. We also reviewed the reference lists of articles and included those articles not already identified by the database search. The endpoints evaluated included perioperative outcomes (operative time, blood loss, transfusion rate, hospital stay, catheter time, and overall complication rates), functional outcomes (urinary continence, potency recovery), and positive surgical margin (PSM) rates and costeffectiveness. Weighted means were calculated for all outcomes using the number of patients included in each study as the weighting factor.

\section{Statistical Methods}

The performance profiles of three surgical operations were characterised by a vector of several variables. Each vector reports aspects used in this dataset for meta-analysis. To achieve a quantitative comparison of the surgical profiles, each variable value was weighted according to the sample size of the study included. A table of adjusted average components of the profile vectors is provided. The comparison addressed the issue of lack of homoscedasticity by performing a weighted OLS regression assuming that the errors have an error distribution of $\varepsilon_{\mathrm{i}} \sim \mathrm{N}\left(0 ; \sigma^{2} / \mathrm{w}_{\mathrm{i}}\right)$, where $\mathrm{w}_{\mathrm{i}}$ represents the known weights, and $\sigma^{2}$ is an unknown parameter that is estimated in the regression. The comparisons of each vector component across the three surgical treatments were significant with most $p<0.05$. Because of the independence of the components, after adjusting for multiple tests (Sidak), we found performance profile vectors that were significantly different at $\mathrm{p}<$ 0.05 .

The statistical analysis was conducted using the software STATA version 13. The global results with standard errors and $\mathrm{p}$ values are reported in table 1 .

\section{Results}

We identified 44 relevant articles in the literature search. Among the 44 evaluated papers, 19 compared RRP with LRP, 19 compared RRP with RALP, 4 compared LRP with RALP, and 2 compared all surgical techniques together. The mean patient age (range) for the RRP, LRP, and RARP series included in the studies was 61.3 (58-65), 62.9 (57.6-64), and 60.4 (59.2-63.5) years, respectively.

\section{Perioperative Outcomes and Postoperative Morbidity}

The results for operative time, blood loss, blood transfusion rates, catheterisation time, hospital stay, and overall complication rates for RRP, LRP, and RALP are presented in table $2[10,14-16,18-25,29,30,32-37,39-43$, $45,48,49,52-55]$.

The weighted mean operative times (range) were 179.03 (105-253) min for the RRP series, 236.54 (144- 
Table 1. Perioperative outcomes and postoperative morbidity

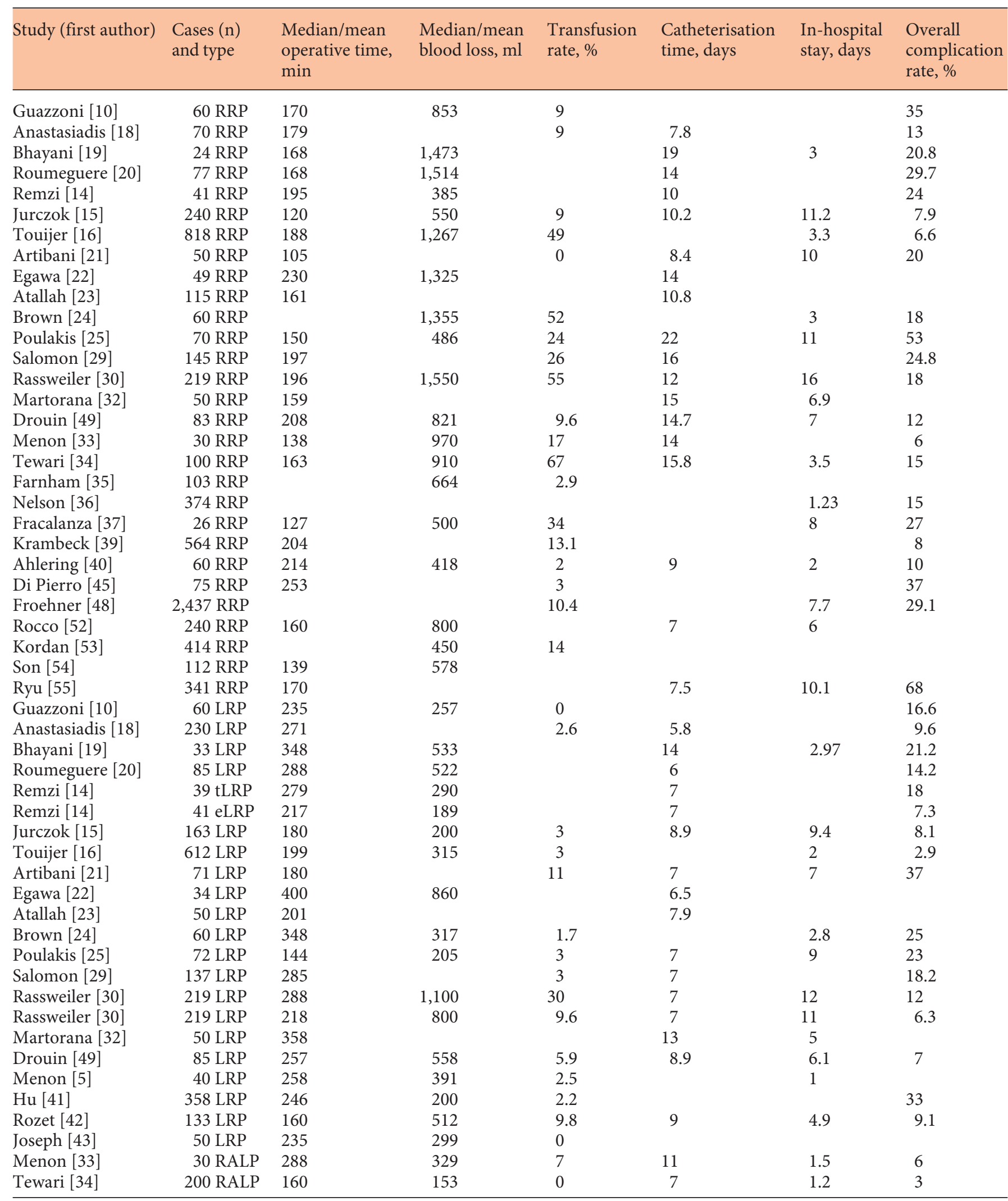


Table 1. (continued)

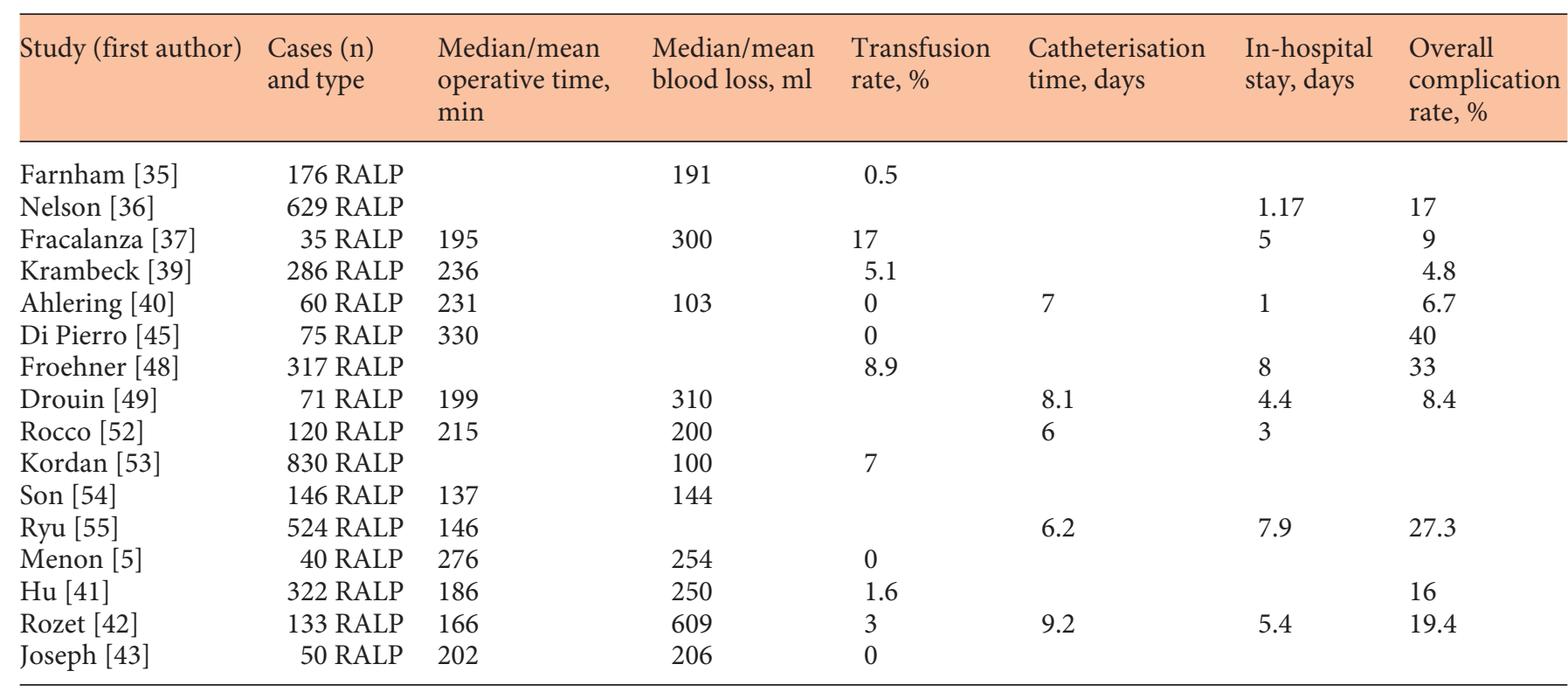

tLRP $=$ Transperitoneal LRP; eLRP = extraperitoneal LRP.

400) $\mathrm{min}$ for the LRP series, and $187.91(137-330) \mathrm{min}$ for the RALP series. The weighted mean estimated blood loss (EBL) for RRP, LRP, and RARP was 935, 442, and $191 \mathrm{ml}$, respectively. The weighted mean intra- and postoperative transfusion rates for RRP, LRP and RARP were 19.93, 6.3, and $4.66 \%$, respectively. In terms of the length of hospital stays, the RRP series had a weighted mean of 7.87 days; the weighted mean hospital stay for LRP and RARP was 6.09 and 3.85 days, respectively. The weighted mean catheterisation time (range) for RRP, LRP, and RARP was 12.85 (1.23-16), 10.32 (1-12), and 6.96 (1-8) days, respectively. The weighted mean for the rate of postoperative complication rates (range) for RRP, LRP, and RARP were $23.2 \%$ (6-68\%), $13.42 \%$ (2.9-37\%), and $18.52 \%$ (3$40 \%)$, respectively.

\section{Functional Outcomes}

Urinary Continence

The postoperative urinary continence outcomes for RARP, LRP, and RRP are shown in table $3[14,16,18$, 20-22, 25, 30, 39, 43, 45, 50, 52, 54].

The evaluation of urinary continence rates between different studies is difficult. This is due mainly to the lack of standard data collection methods (the use of non-validated questionnaires or simple interviews) and the use of different definitions. Furthermore, follow-up is often insufficient or only partial.
In our study, we identified continence as the use of no absorbent pads or no leakage at all. We identified 14 studies with reported and comparable urinary continence rates (uncompleted outcomes at 6,12 , and 24 months). Evaluating RRP, the weighted mean continence rates were 73.71 and $83.22 \%$ at 6 and 12 months of follow-up, respectively. Only 2 studies evaluated incontinence at 24 months of follow-up (both found $82 \%$ continence rates). The LRP-weighted mean continence rates were 63.8 and $70.7 \%$ at 6 and 12 months of follow-up, respectively; only one study evaluated incontinence at 24 months of followup and reported a continence rate of $62 \%$. Finally, RARP patients had continence rates, at 6 and 12 months of follow-up, of 89.12 and $92.78 \%$, respectively. Only one study evaluated incontinence at 24 months of follow-up in the RALP series, and it reported a continence rate of $95.2 \%$.

\section{Erectile Function}

The postoperative erectile function outcomes for RRP, LRP, and RARP are shown in table $3[14,16,18,20-22$, $25,30,39,43,45,50,52,54]$.

Among the 44 comparative studies analysed, only 8 provide accurate erectile function data, and only 2 papers used a validated questionnaire, such as the International Index of Erectile Function (IIEF) [9]; all other studies used non-validated questionnaires or open interviews. The RRP-weighted mean potency rates at 3, 12, and 24 
Table 2. Functional outcomes (continence and potency)

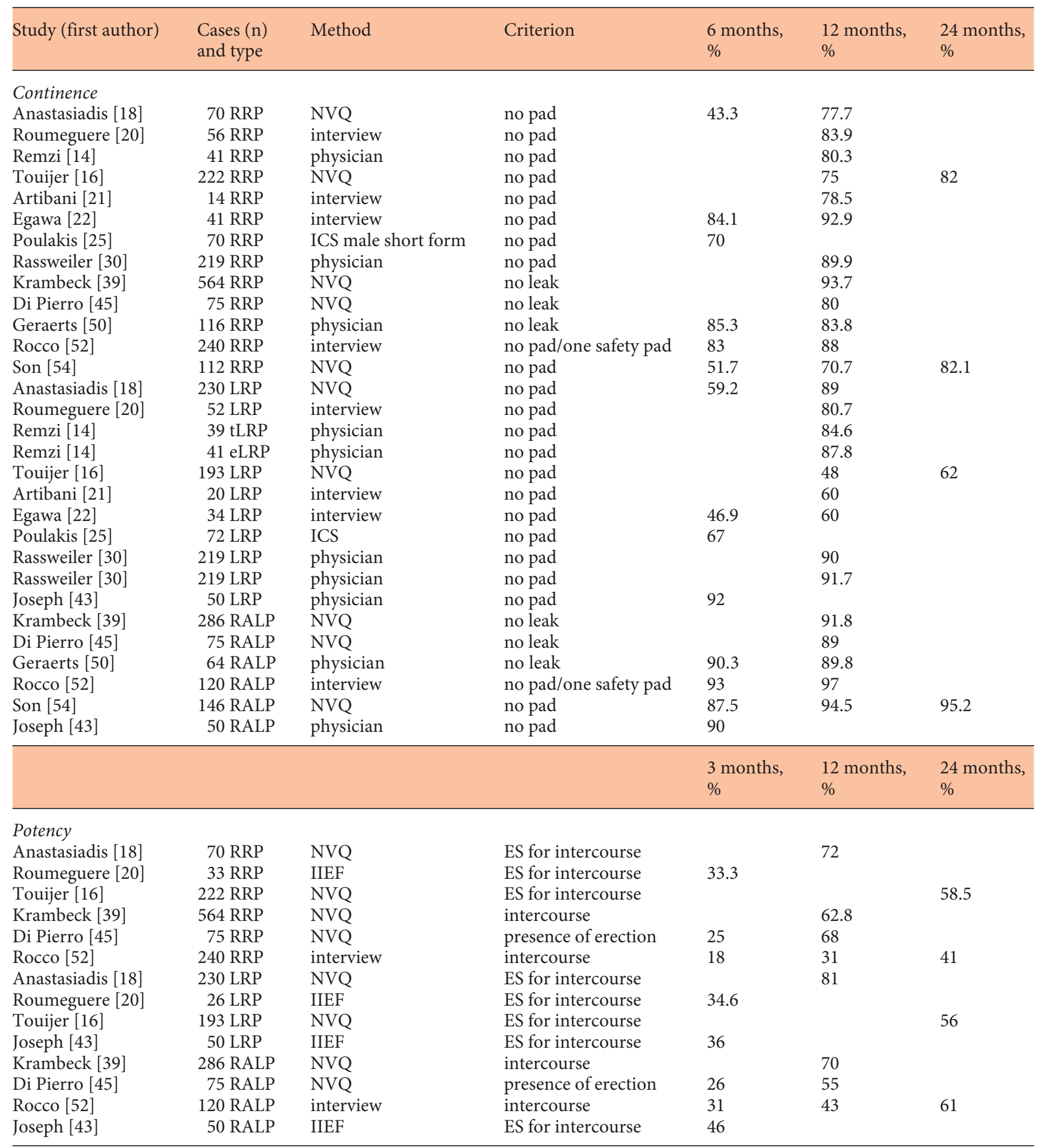

NVQ = Non-validated questionnaire; ES = erection sufficient; tLRP = transperitoneal LRP; eLRP = extraperitoneal LRP.

Retropubic, Laparoscopic, and

Robot-Assisted Radical Prostatectomy 
Table 3. Oncological outcomes

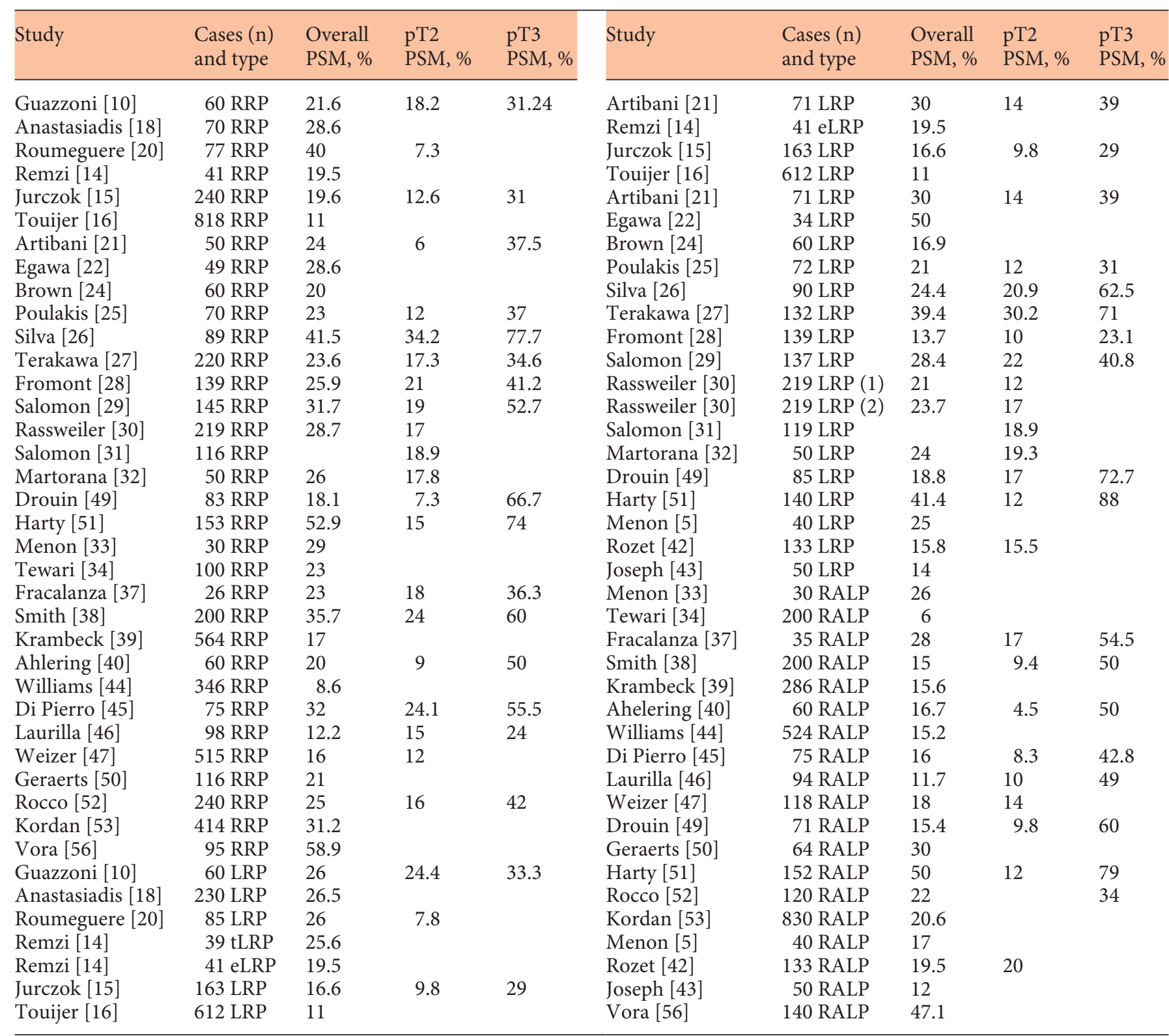

tLRP = Transperitoneal LRP; eLRP = extraperitoneal LRP.

months were $22.34,55.85$ and $54.53 \%$, respectively. The LRP-weighted mean potency rate at 3 months of followup was $35.12 \%$; potency rates at 12 and 24 months of follow-up were each only reported by one paper (81 and $56 \%$, respectively). Regarding RALP, patients displayed potency rates at 3 and 12 months of follow-up of 32.53 and $60.93 \%$, respectively. Only one article included a 24 -month potency follow-up (61\% potency rate at 24 months). Unfortunately, the same lack of standardisa- tion seen for urinary continence can be noted in the erectile function analysis. Very often, collected data are incomparable among studies, or the follow-up period is too short.

\section{Oncological Outcomes}

The PSM rates for RRP, LRP, and RALP series are summarised in table $4[10,14-16,18,20-22,24-34,36-$ $39,42-47,49-53,56]$. 
Table 4. Statistical analysis (global results expressed as weighted mean)

\begin{tabular}{|c|c|c|c|c|}
\hline & \multicolumn{3}{|l|}{ Study } & \multirow[t]{2}{*}{$\mathrm{p}$ value } \\
\hline & RRP & LRP & RALP & \\
\hline Operative time, $\min$ & 179.03 & 236.54 & 187.91 & 0.0000 \\
\hline SE & 0.47 & 0.97 & 1.02 & \\
\hline Blood loss, $\mathrm{ml}$ & 935.86 & 442.32 & 191.03 & 0.0000 \\
\hline SE & 7.36 & 5.88 & 2.65 & \\
\hline Transfusion rate, $\%$ & 19.93 & 6.3 & 4.66 & 0.0011 \\
\hline SE & 0.23 & 0.16 & 0.07 & \\
\hline Catheterisation time, days & 12.85 & 10.32 & 6.96 & 0.0000 \\
\hline SE & 0.22 & 0.35 & 0.04 & \\
\hline In-hospital stay, days & 7.87 & 9.02 & 5.87 & 0.0000 \\
\hline SE & 0.13 & 0.37 & 0.23 & \\
\hline Overall complication rate, $\%$ & 23.2 & 13.42 & 18.52 & 0.0000 \\
\hline SE & 0.19 & 0.21 & 0.19 & \\
\hline Continence 6 months, $\%$ & 73.71 & 63.82 & 89.12 & 0.0000 \\
\hline SE & 0.52 & 0.61 & 0.24 & \\
\hline Continence 12 months, \% & 83.22 & 70.77 & 92.78 & 0.0015 \\
\hline SE & 0.16 & 0.5 & 0.1 & \\
\hline Continence 24 months, \% & $\mathrm{NE}$ & $\mathrm{NE}$ & 95.2 & 3.542361111 \\
\hline SE & & & 0.01 & \\
\hline Potency 3 months, \% & 22.34 & 35.12 & 32.53 & 0.0000 \\
\hline $\mathrm{SE}$ & 0.31 & 0.06 & 0.46 & \\
\hline Potency 12 months, \% & 55.85 & $\mathrm{NE}$ & 60.93 & 3.266666667 \\
\hline SE & 0.48 & & 0.53 & \\
\hline Potency 24 months, \% & 54.53 & $\mathrm{NE}$ & $\mathrm{NE}$ & 5.521527778 \\
\hline SE & 0.23 & & & \\
\hline Overall PSM, \% & 22.45 & 22.04 & 21.14 & 0.0000 \\
\hline SE & 0.14 & 0.18 & 0.24 & \\
\hline pT2 PSM, \% & 16.64 & 17.44 & 10.53 & 0.314583333 \\
\hline SE & 0.11 & 0.16 & 0.1 & \\
\hline pT3 PSM, \% & 46.75 & 49.61 & 53.37 & 0.2433 \\
\hline SE & 0.35 & 0.68 & 0.5 & \\
\hline
\end{tabular}

$\mathrm{SE}=$ Standard error; $\mathrm{NE}=$ not evaluable.

RALP revealed a weighted mean overall PSM rate of 21.14\%, whereas LRP and RRP yielded PSMs of 22.04 and $22.45 \%$, respectively. Analysing only pT2 stage tumours, we found that RALP, LRP, and RRP had PSM rates of $10.53,17.44$, and $16.64 \%$, respectively, whereas for pT3 stage tumours, we obtained PSM rates of 53.37, 49.61 and $46.75 \%$ for RALP, LRP and RRP, respectively. The statistical analysis of all of the comparative studies reporting data on PSM rates suggests that the PSM rates were similar for RRP versus LRP; on the contrary, statistical analysis of all of the comparative studies reporting data on RRP and LRP versus RALP margin status indicates a significant difference in favour of RALP. However, despite the available state-of-the-art techniques, this study found a controversial outcome. No final conclusions can be drawn from these findings, and more studies are needed to fully answer the question of superiority.

\section{Discussion}

It is very difficult to compare open RP with the laparoscopic and robotic approaches because the available clinical studies have several limitations. Almost all of the available data derive from prospective, non-randomised, or retrospective studies, which provide a low level of evidence.

Performing a randomised controlled trial is clearly a very difficult task, as many patients cannot be randomised on surgical approach because most of them are unwilling 
to accept the idea of randomisation to a particular surgical treatment and are usually quite fascinated by the most modern surgical procedure or chose a procedure based on personal preferences for a specific surgeon. A patient has no choice of surgical approach only when their medical condition does not permit particular techniques. In this context, in those units that perform several techniques simultaneously, patients with low-risk disease more often underwent RARP, whereas almost all patients with high-risk disease ( $\geq$ CT3, PSA $\geq 20$ and Gleason score $\geq 8$ ) underwent open surgery because they required an extended lymph node dissection.

Among the few randomised controlled trials, Guazzoni et al. [10] demonstrated that LRP has advantages over RRP in terms of reduced blood loss and a higher percentage of safe early catheter removal, with comparable oncologic results in terms of positive margins rates. Porpiglia et al. [11] demonstrated in their randomised controlled trial the advantage of RALP on LRP approaches in terms of the recovery of continence and potency.

Centres performing laparoscopic or robotic surgery usually focus mainly on these approaches, abandoning or limiting considerably their practice using traditional open surgery. Consequently, in many papers, historical instead of contemporary controls for RRP are used leading for an unfit comparison with the more recent minimally invasive procedures database. Moreover, though in many studies RRPs were performed by several surgeons with varying levels of expertise, laparoscopic or robotic procedures were usually performed by a small number of dedicated urologists. Furthermore, some of the comparative studies excluded the early learning curve of the miniinvasive RP, introducing further bias. This issue has particular significance if we consider that the LRP approach, more so than the robotic approach, suffers from a long learning curve. Whereas the RALP is more intuitive, the restrictions related to LRP, including the reduction of the range of motion, two-dimensional vision, impaired eyehand coordination (i.e. misorientation between real and visible movements), and reduced haptic sense, lead to a steep learning curve. Finally, definitions used to describe positive margins, such as urinary continence and sexual functioning, are not standardised and may differ significantly between the series.

\section{Pelvic Lymph Node Dissection}

Pelvic lymph node dissection (PLND) is a controversial aspect of RP. Controversies exist regarding both the patients who should undergo PLND and the extent of nodal dissection.
Prediction models have been created to assess the risk of lymph node involvement and help guide practitioners in making more informed decisions [12]. According to the NCCN guidelines, a PLND can be excluded in patients with $<2 \%$ predicated probability of nodal metastases by nomograms. However, with the increasing prevalence of RALP in urological practice, the feasibility of PLND as well as the adequacy of nodal yield have been investigated. It has been demonstrated that patients undergoing RRP are more likely to have concomitant PLND compared with patients undergoing RALP, based on various factors such as surgical volume, robotic learning curve, operative time, and cost [13].

Lymph node status was not included in this study because this information was often unavailable. Only 4 of 44 of the papers (9\%) reported PLND data. Guazzoni et al. [10] limited pelvic lymphadenectomy at patients with total serum PSA level $>10 \mathrm{ng} / \mathrm{ml}$ and/or Gleason score $=7$ (45\% of RRP and $40 \%$ of LRP). Remzi et al. [14] proceeded to PLND in all laparoscopic patients, staging lymphadenectomy of the obturator fossa and in only $71 \%$ of RRP (PSA $>10 \mathrm{ng} /$ $\mathrm{ml}$, Gleason score $>6$ ) with no nodal involvement reported. Jurczok et al. [15] and Touijer et al. [16] extended PLND to all patients regardless of their risk stratification.

In the future, continued emphasis must be placed on performing PLND during RP by all surgical approaches in all prostate cancer patients with $>2 \%$ risk of lymph node involvement, as presently recommended by NCCN guidelines.

\section{Perioperative Data}

The main perioperative parameters evaluated to compare the retropubic, laparoscopic and robotic approach to $\mathrm{RP}$ were operative time, blood loss, transfusion rates, duration of hospital stay, catheterisation time, and overall complication rate. It is difficult to compare operative times among different series because of variations in reporting operative time (the inclusion of setup time and/or PLND).

In our study, the weighted mean operative time was shorter for RRP (179.03 min), whereas the operative times for both LRP and RALP were longer (236 and 187 min, respectively) with little difference between RALP and RRP sessions $(\mathrm{p}=0.000)$. Such differences between LRP and RRP are significantly larger during the initial phase of the learning curve, but they decrease with experience. The data in the literature indicate that RALP simplifies the learning process, allowing faster reduction in operative time compared with pure LRP.

Decreased intraoperative blood loss is a reported great advantage of laparoscopic/robot-assisted prostatectomy. 
Currently, plexus Santorini is mostly well controlled. Bleeding originates more frequently from dorsolateral vessels maintained during nerve-sparing. Moreover, the tamponade effect created by pneumoperitoneum and the early identification and precise ligation of vessels helps diminish blood loss. Our findings indicate that RALP facilitated a significant reduction in blood loss with consequent lower perioperative transfusion rates compared with RRP (mean EBL 191 vs. $935 \mathrm{ml}$, respectively, and transfusion rates 4.66 and $19.93 \%$, respectively, $\mathrm{p}=0.000$ ). Similarly, transfusion rates were significantly lower in patients undergoing LRP compared with RRP (mean EBL 442 vs. 935 $\mathrm{ml}$, respectively, and transfusion rates 6.3 and $19.93 \%$, respectively, $\mathrm{p}=0.000$ ). Alternatively, LRP and RALP performed similarly with regard to blood loss and transfusion rates (mean EBL 442 vs. $191 \mathrm{ml}$, respectively, and transfusion rates 6.3 and $4.66 \%$, respectively, $\mathrm{p}=0.000$ ).

A large variability in the duration of hospitalisation and catheterisation time was observed in the evaluated series, which most likely reflected the differences in the location where the series were carried out. In Europe, patients often stay in the hospital until the urinary catheter is removed, whereas in the United States, the patients are usually discharged quickly after surgery.

The main comparative studies indicate that the robotic approach has significant advantages, mainly in terms of in-hospital stay but also for catheterisation time. The mean in-hospital stay was higher for the RRP and LRP series than in the RALP series in our review $(7.87,6.09$, and 3.85 days, respectively, $\mathrm{p}=0.000$ ). The mean catheterisation time displayed better results for RALP compared with LRP and $\operatorname{RRP}(6.96,10.32$, and 12.85 days, respectively, $\mathrm{p}=$ 0.000 ). Our hypothesis regarding the other perioperative parameters is confirmed for the overall complication rates.

Data from comparative studies indicate a significant advantage for the RALP and LRP series in comparison with the RRP series when evaluating complication rates $(18.52 \%$ vs. 13.42 and $23.2 \%$, respectively, $p=0.000)$, with LRP having the best results. We can say that once the learning curve is completed, LRP and RALP can be performed without a significant risk of major complications and with better results than RRP.

\section{Functional Outcomes}

The evaluation of continence outcomes after RP remains difficult due to the lack of standardisation among series. Only a few of the available comparative studies used validated questionnaires, and the outcomes were often assessed by an open interview. Furthermore, followup is often insufficient or only partial. In this situation, only trends can be suggested as to whether any particular approach delivers superior continence outcomes.

In our review, the weighted mean continence rates at 6 months for the RRP, LRP, and RARP series were 73.71, 63.82 , and $89.12 \%$, respectively $(\mathrm{p}=0.000)$. Aftera 12 -month follow-up, the continence rates for the RRP, LRP, and RALP series were $83.22,70.77$, and $92.78 \%$, respectively $(\mathrm{p}=0.001)$. Evaluation at 24 months of follow-up was impossible because few papers conducted follow-up using this interval ( 2 studies for RRP and 1 study for LRP and RALP).

Our data support the statement that the continence rates after RRP and LRP were similar, with RRP performing slightly better than LRP. The RARP continence rates were higher in our study when compared with RRP and LRP. Randomised prospective studies are necessary, however, to accurately compare the continence rates between the three surgical approaches.

Regarding potency rates, the data are too limited for evaluation. In our review, data from the available comparative studies suggested an advantage in terms of urinary continence and erectile function for patients who underwent RALP compared with those patients subjected to the RRP and LRP techniques, but future studies are needed to confirm this trend.

\section{Oncological Outcomes}

PSMs are the most used and collected data for oncological RP analysis. This is mainly because of the lack of long-term biochemical recurrence and disease-free survival rate data. In our study, we analysed the overall PSM rates and pT2 PSM rates among comparative studies. We found similar PSM rates for RRP and LRP (22.45 and $22.04 \%$, respectively, $\mathrm{p}=0.000$ ), whereas RALP was only slightly better compared with the other techniques (21.14\%). These differences become significant if we consider only the pT2 stage with similar rates for the RRP and LRP series (16.64 and $17.44 \%$ pT2 PSM rates, respectively, $\mathrm{p}=0.045)$ and lower rates for RALP (10.53\% pT2 PSM rates). Randomised trials are necessary, however, before definitive conclusions can be reached.

\section{Cost}

The use of robot-assisted laparoscopic prostatectomy introduces another issue. The cost for a single procedure with RALP is much higher for the cost of LRP or RRP. As Bolenz et al. [8] have demonstrated, the median direct cost is higher for RALP compared with LRP or RRP (RALP, USD 6,752; LRP, USD 5,687; RRP, USD 4,437). The main difference is in the cost of surgical supplies (RALP, USD 2,015; LRP, USD 725; RRP, USD 185) and operating room 
costs (RALP, USD 2,798; LRP, USD 2,453; RRP, USD 1,611). When considering the purchase of and maintenance costs for the robot, the financial burden increases by USD 2,698 per patient. Close et al. [17] also found worse economic results (robotic prostatectomy was on average GBP 1,412 more expensive than laparoscopic prostatectomy). These results are similar to those of other comparative studies. The financial standpoint must be considered just as much as the other surgical outcomes in choosing surgical techniques.

\section{Conclusion}

The evaluation and comparison of RP techniques is very difficult. We can state that pure LRPs and RALPs have significantly lower blood loss and transfusion rates and have all of the traditional advantages of minimally invasive procedures. However, even if data from this systematic review suggest better results for RALP in terms of functional and oncologic outcomes, to date there is no certain proof of its superiority. Contrasting results among comparative studies associated with the lack of randomised trials and long-term follow-up studies that com- pare the three approaches precludes definitive conclusions. It is likely that the surgeon's experience, rather than the surgical approach, can best determine the surgical results. For example, an LRP performed by a qualitatively poor surgeon would not be superior to an RRP performed by a skilled surgeon (and vice versa).

To date there is no reason that a surgeon obtaining excellent functional and oncologic results with RRP should switch to a different approach. Alternatively, surgeons obtaining suboptimal results might improve them by shifting to a different approach. On the other hand, cost comparison merits special mention. The exponential growth of medical costs globally, linked with the use of increasingly more expensive technologies, makes it necessary to search for diagnostic and therapeutic tools that ensure the best possible result with the least possible expense to make the best available treatment accessible to the entire population. Currently, the cost for a single RALP procedure is much higher than for LRP or RRP. In this context, the use of robotic technology should be limited to centres dealing with a high volume of prostate cancer. Moreover, growing competition among robotic technology producers is bound to lower the overall cost.

\section{References}

1 Heidenreich A, Aus G, Bolla M, Joniau S, Mason M, Matveev V, Mottet N, Schmid H, van der Kwast T, Wiegel T, Zattoni F: EAU guidelines on prostate cancer. Part 1: Screening, diagnosis, and treatment of clinically localised disease. Eur Urol 2011;59:61-71.

$\checkmark 2$ Schuessler W, Sculam P, Clayman R, Kavoussi L: Laparoscopic radical prostatectomy: initial short-term experience. Urology 1997;50: 854-857.

$>3$ Guillonneau B, Vallancien G: Laparoscopic radical prostatectomy: the Montsouris technique. J Urol 2000;163:1643-1649.

4 Rassweiler J, Hruza M, Teber D, Su LM: Laparoscopic and robotic assisted radical prostatectomy - critical analysis of the results. Eur Urol 2006;49:612-624.

$>5$ Menon M, Shrivastava A, Tewari A, Sarle R, Hemal A, Peabody J, Vallancien G: Laparoscopic and robot assisted radical prostatectomy: establishment of a structured program and preliminary analysis of outcomes. J Urol 2002;168:945-949.

-6 Ficarra V, Cavalleri S, Novara G, Aragona M, Artibani W: Evidence from robot-assisted laparoscopic radical prostatectomy: a systematic review. Eur Urol 2007;51:45-56.

$\checkmark 7$ Artibani W, Cavalleri S, Iafrate $M$, et al: Learning curve of an experienced open surgeon with da Vinci-assisted laparoscopic rad- ical prostatectomy. Urol Int 2008;80:237244.

8 Bolenz C, Freedland S, Hollenbeck B, Lotan Y, Lowrance W, Nelson J, Hu JC: Costs of radical prostatectomy for prostate cancer: a systematic review. Eur Urol 2014;65:316-324.

$>9$ Rosen RC, Riley A, Wagner G, Osterloh IH, Kirkpatrick J, Mishra A: The International Index of Erectile Function (IIEF): a multidimensional scale for assessment of erectile dysfunction. Urology 1997;49:822-830.

-10 Guazzoni G, Cestari A, Naspro R, et al: Intraand perioperative outcomes comparing radical retropubic and laparoscopic radical prostatectomy: results from a prospective, randomised, single-surgeon study. Eur Urol 2006;50:98-104.

$>11$ Porpiglia F, Morra I, Lucci Chiarissi M, et al: Randomised controlled trial comparing laparoscopic and robot-assisted radical prostatectomy. Eur Urol 2013;63:606-614.

12 Cagiannos I, Karakiewicz P, Eastham JA, et al: A preoperative nomogram identifying decreased risk of positive pelvic lymph nodes in patients with prostate cancer. J Urol 2003;170: 1798-1803.

13 Prasad SM, Keating NL, Wang Q, et al: Variations in surgeon volume and use of pelvic lymph node dissection with open and minimally invasive radical prostatectomy. Urology $2008 ; 72: 647-652$.
14 Remzi M, Klingler HC, Tinzl MV, et al: Morbidity of laparoscopic extraperitoneal versus transperitoneal radical prostatectomy versus open retropubic radical prostatectomy. Eur Urol 2005;48:83-89.

15 Jurczok A, Zacharias M, Wagner S, Hamza A, Fornara P: Prospective non-randomized evaluation of four mediators of the systemic response after extraperitoneal laparoscopic and open retropubic radical prostatectomy. BJU Int 2007;99:1461-1466.

16 Touijer K, Eastham JA, Secin FP, et al: Comprehensive prospective comparative analysis of outcomes between open and laparoscopic radical prostatectomy conducted in 2003 to 2005. J Urol 2008;179:1811-1817.

17 Close A, Robertson C, Rushton S, Shirley M, Vale L, Ramsay C, Pickard R: Comparative cost-effectiveness of robot-assisted and standard laparoscopic prostatectomy as alternatives to open radical prostatectomy for treatment of men with localised prostate cancer: a health technology assessment from the perspective of the UK National Health Service. Eur Urol 2013;64:361-369.

18 Anastasiadis AG, Salomon L, Katz R, Hoznek A, Chopin D, Abbou CC: Radical retropubic versus laparoscopic prostatectomy: a prospective comparison of functional outcome. Urology 2003;62:292-297. 
19 Bhayani SB, Pavlovich CP, Hsu TS, Sullivan W, Su LM: Prospective comparison of shortterm convalescence: laparoscopic radical prostatectomy versus open radical retropubic prostatectomy. Urology 2003;61:612-616.

20 Roumeguere T, Bollens R, Vanden Bossche $\mathrm{M}$, et al: Radical prostatectomy: a prospective comparison of oncological and functional results between open and laparoscopic approaches. World J Urol 2003;20:360-366.

21 Artibani W, Grosso G, Novara G, et al: Is laparoscopic radical prostatectomy better than traditional retropubic radical prostatectomy? An analysis of perioperative morbidity in two contemporary series in Italy. Eur Urol 2003; 44:401-406

22 Egawa S, Kuruma H, Suyama K, Iwamura M, Baba S: Delayed recovery of urinary continence after laparoscopic radical prostatectomy. Int J Urol 2003;10:207-212.

23 Atallah F, Khedis M, Seguin P, Fourcade O, Samii K: Postoperative analgesia and recovery after open and laparoscopic prostatectomy Anesth Analg 2004;99:1878-1879.

-24 Brown JA, Garlitz C, Gomella LG, McGinnis DE, Diamond SM, Strup SE: Perioperative morbidity of laparoscopic radical prostatectomy compared with open radical retropubic prostatectomy. Urol Oncol 2004;22:102-106.

-25 Poulakis V, Witzsch U, de Vries R, Dillenburg W, Becht E: Laparoscopic radical prostatectomy in men older than 70 years of age with localized prostate cancer: comparison of morbidity, reconvalescence, and short-term clinical outcomes between younger and older men. Eur Urol 2007;51:1341-1349.

26 Silva E, Ferreira U, Silva GD, et al: Surgical margins in radical prostatectomy: a comparison between retropubic and laparoscopic surgery. Int Urol Nephrol 2007;39:865-869.

-27 Terakawa T, Miyake H, Tanaka K, Takenaka A, Inoue TA, Fujisawa M: Surgical margin status of open versus laparoscopic radical prostatectomy specimens. Int J Urol 2008; 15 : 704-707.

-28 Fromont G, Guillonneau B, Validire P, Vallancien G: Laparoscopic radical prostatectomy. Preliminary pathologic evaluation. Urology 2002;60:661-665.

29 Salomon L, Levrel O, de la Taille A, et al: Radical prostatectomy by the retropubic, perineal and laparoscopic approach: 12 years of experience in one center. Eur Urol 2002;42:104111.

-30 Rassweiler J, Seemann O, Schulze M, Teber D, Hatzinger M, Frede T: Laparoscopic versus open radical prostatectomy: a comparative study at a single institution. J Urol 2003;169: 1689-1693.

- 31 Salomon L, Anastasiadis AG, Levrel O, et al: Location of positive surgical margins after retropubic, perineal, and laparoscopic radical prostatectomy for organ-confined prostate cancer. Urology 2003;61:386-390.

- 32 Martorana G, Manferrari F, Bertaccini A, et al: Laparoscopic radical prostatectomy: oncological evaluation in the early phase of the learning curve comparing to retropubic approach. Arch Ital Urol Androl 2004;76:1-5.

33 Menon M, Tewari A, Baize B, Guillonneau B, Vallancien G: Prospective comparison of radical retropubic prostatectomy and robot-assisted anatomic prostatectomy: the Vattikuti Urology Institute experience. Urology 2002; 60:864-868.

34 Tewari A, Srivasatava A, Menon M: A prospective comparison of radical retropubic and robot-assisted prostatectomy: experience in one institution. BJU Int 2003;92:205210.

35 Farnham SB, Webster TM, Herrell SD, Smith JA Jr: Intraoperative blood loss and transfusion requirements for robotic-assisted radical prostatectomy versus radical retropubic prostatectomy. Urology 2006;67:360-363.

- 36 Nelson B, Kaufman M, Broughton G, et al: Comparison of length of hospital stay between radical retropubic prostatectomy and robotic assisted laparoscopic prostatectomy. J Urol 2007;177:929-931

- 37 Fracalanza S, Ficarra V, Cavalleri S, et al: Is robotically assisted laparoscopic radical prostatectomy less invasive than retropubic radical prostatectomy? Results from a prospective, unrandomized, comparative study. BJU Int 2008;101:1145-1149.

38 Smith JA Jr, Chan RC, Chang SS, et al: A comparison of the incidence and location of positive surgical margins in robotic assisted laparoscopic radical prostatectomy and open retropubic radical prostatectomy. J Urol 2007; 178:2385-2389.

-39 Krambeck AE, DiMarco DS, Rangel LJ, et al: Radical prostatectomy for prostatic adenocarcinoma: a matched comparison of open retropubic and robot-assisted techniques. BJU Int 2009;103:448-453.

40 Ahlering TE, Woo D, Eichel L, Lee DI, Edwards R, Skarecky DW: Robot-assisted versus open radical prostatectomy: a comparison of one surgeon's outcomes. Urology 2004;63: 819-822.

$41 \mathrm{Hu}$ JC, Nelson RA, Wilson TG, et al: Perioperative complications of laparoscopic and robotic assisted laparoscopic radical prostatectomy. J Urol 2006;175:541-546.

42 Rozet F, Jaffe J, Braud G, et al: A direct comparison of robotic assisted versus pure laparoscopic radical prostatectomy: a single institution experience. J Urol 2007;178:478-482.

-43 Joseph JV, Vicente I, Madeb R, Erturk E, Patel HR: Robot-assisted versus pure laparoscopic radical prostatectomy: are there any differences? BJU Int 2005;96:39-42.

44 Williams SB, Chen MH, D’Amico AV, Weinberg AC, Kacker R, Hirsch MS, Richie JP, Hu JC: Radical retropubic prostatectomy and robotic-assisted laparoscopic prostatectomy: likelihood of positive surgical margin(s). Urology 2010;76:1097-1101.

45 Di Pierro GB, Baumeister P, Stucki P, Beatrice J, Danuser H, Mattei A: A prospective trial comparing consecutive series of open retropubic and robot-assisted laparoscopic radical prostatectomy in a centre with a limited caseload. Eur Urol 2011;59:1-6.

46 Laurilla TAJ, Huang W, Jarrard DF: Roboticassisted laparoscopic and radical retropubic prostatectomy generate similar positive margin rates in low and intermediate risk patients. Urol Oncol 2009;27:529-533.

47 Weizer AZ, Strope S, Wood DP: Margin control in robotic and laparoscopic prostatectomy: What are the REAL outcomes? Urol Oncol 2010;28:210-214.

48 Froehner M, Novotny V, Koch R, Leike S, Twelker L, Wirth MP: Perioperative complications after radical prostatectomy: open versus robot-assisted laparoscopic approach. Urol Int 2013;90:312-315.

49 Drouin SJ, Vaessen C, Hupertan V, Comperat E, Misraï V, Haertig A, Bitker M-C, ChartierKastler E, Richard F, Rouprêt M: Comparison of mid-term carcinologic control obtained after open, laparoscopic, and robot-assisted radical prostatectomy for localized prostate cancer. World J Urol 2009;27:599-605.

50 Geraerts I, Van Poppel H, Devoogdt N, Van Cleynenbreugel B, Joniau S, Van Kampen M: Prospective evaluation of urinary incontinence, voiding symptoms and quality of life after open and robot-assisted radical prostatectomy. BJU Int 2013;112:936-943.

51 Harty NJ, Kozinn SI, Canes D, Sorcini A, Moinzadeh A: Comparison of positive surgical margin rates in high risk prostate cancer: open versus minimally invasive radical prostatectomy. Int Braz J Urol 2013;39:639-646.

52 Rocco B, Matei DV, Melegari S, Ospina JC, Mazzoleni F, Errico G, Mastropasqua M, Santoro L, Detti S, De Cobelli O: Robotic vs. open prostatectomy in a laparoscopically naive centre: a matched-pair analysis. BJU Int 2009; 104:991-995.

53 Kordan Y, Barocas DA, Altamar HO, Clark PE, Chang SS, Davis R, Duke Herrell S, Baumgartner R, Mishra V, Chan RC, Smith JA, Cookson MS: Comparison of transfusion requirements between open and robotic-assisted laparoscopic radical prostatectomy. BJU Int 2010;106:1036-1040.

54 Son SJ, Lee SC, Jeong CW, Jeong SJ, Byun SS, Lee SE: Comparison of continence recovery between robot-assisted laparoscopic prostatectomy and open radical retropubic prostatectomy: a single surgeon experience. Korean J Urol 2013;54:598-602.

55 Ryu J, Kwon T, Kyung YS, Hong S, You D, Jeong IG, Kim C-S: Retropubic versus robotassisted laparoscopic prostatectomy for prostate cancer: a comparative study of postoperative complications. Korean J Urol 2013;54: 756-761.

56 Vora AA, Marchalik D, Kowalczyk KJ, Nissim H, Bandi G, McGeagh KG, Lynch GH, Ghasemian SR, Verghese M, Venkatesan K, Borges P, Uchio EM, Hwang JJ: Robotic-assisted prostatectomy and open radical retropubic prostatectomy for locally-advanced prostate cancer: multi-institution comparison of oncologic outcomes. Prostate Int 2013;1:31-36.
Retropubic, Laparoscopic, and

Robot-Assisted Radical Prostatectomy 